\title{
CORRIGENDUM \\ The phenotypic correlates and quantitative genetics of masculinization in the rodent, Octodon degus
}

\author{
DA Roff, ME Wolak, LA Correa and M Soto-Gamboa \\ Heredity (2017) 119, 206; doi:10.1038/hdy.2017.35; published online 26 July 2017
}

Correction to: Heredity (2017) 119, 136-141; doi:10.1038/hdy.2017.20; published online 12 April 2017

In the above paper we inadvertently omitted the denominator from the weight AIC estimate: the estimator in the paper is given as $\beta=\sum_{i=1}^{10} w_{i} \beta_{i}$, where $\beta_{i}$ is the (co)variance estimate for the $i$ th model. The correct model is $\beta=\sum_{i=1}^{R} w_{i} \beta_{i} / \sum_{i=1}^{R} w_{i}$ where $R$ is the number of models that contain the relevant parameter. This correction slightly changes the values given in Table 5 but does not in any way affect the conclusions.

The summed Akaike weights for birth weight in males was erroneously reported, the correct values being 0.923 for $V_{\mathrm{a}}, 0.507$ for $V_{\mathrm{m}}$, 0.149 for $C o v_{a m}$ and 0.381 for $V_{c}$. The only change in interpretation is that there is now strong evidence for additive genetic variance for both birth weight and weaning weight in males as was also found in females.

Table 5 (Co)variance and heritability estimates (s.e. in parentheses) for the model(s) with the lowest AIC (shown in bold font)

\begin{tabular}{|c|c|c|c|c|c|c|c|c|}
\hline \multirow[t]{2}{*}{ Model } & \multicolumn{4}{|c|}{ Female } & \multicolumn{4}{|c|}{ Male } \\
\hline & Birth wt & $A G D$ at birth & Weaning wt & $A G D$ at weaning & Birth wt & $A G D$ at birth & Weaning wt & $A G D$ at weaning \\
\hline \multicolumn{9}{|c|}{ (Co)variances } \\
\hline \multirow[t]{2}{*}{$V_{a}$} & $0.77(0.35)$ & $0.50(0.23)$ & $0.28(0.17)$ & $0.04(0.06)$ & $0.29(0.17)$ & $0.06(0.06)$ & $0.52(0.24)$ & $0.43(0.30)$ \\
\hline & $0.75(0.35)$ & $0.41(0.24)$ & $0.34(0.20)$ & $0.04(0.04)$ & $0.30(0.19)$ & & $0.52(0.24)$ & $0.47(0.25)$ \\
\hline$V_{\mathrm{m}}$ & $0.46(0.18)$ & $0.36(0.13)$ & $0.05(0.17)$ & $0.01(0.03)$ & $0.16(0.08)$ & $0.10(0.05)$ & $0.47(0.15)$ & $0.55(0.35)$ \\
\hline \multirow[t]{2}{*}{$\mathrm{Cov}_{\mathrm{am}}$} & $-0.53(0.22)$ & $-0.31(0.15)$ & $-0.08(0.08)$ & $-0.04(0.02)$ & $0.10(0.12)$ & $0.03(0.05)$ & $0.02(0.21)$ & $-0.48(0.37)$ \\
\hline & $-0.49(0.22)$ & $-0.29(0.14)$ & & & & & & $-0.45(0.20)$ \\
\hline \multirow[t]{2}{*}{$V_{c}$} & $0.14(0.08)$ & $0.04(0.02)$ & $0.46(0.14)$ & $0.01(0.01)$ & $0.16(0.08)$ & $0.10(0.05)$ & $0.47(0.15)$ & $0.17(0.06)$ \\
\hline & & & $0.47(0.16)$ & & $0.15(0.05)$ & $0.08(0.04)$ & $0.47(0.10)$ & \\
\hline \multicolumn{9}{|c|}{ Heritabilities $^{a}$} \\
\hline
\end{tabular}

Abbreviations: AGD, anogenital distance; AIC, Akaike information criterion; CoVam, covariance between $V_{\mathrm{a}}$ and $V_{\mathrm{m}} ; V_{\mathrm{a}}$, additive genetic variance; $V_{\mathrm{c}}$, common environmental variance; $V_{\mathrm{m}}$, additive maternal genetic variance; wt, weight.

${ }^{a} h_{\mathrm{T}}^{2}$ : total additive heritability; $h^{2}$ : direct additive heritability; $h_{\mathrm{m}}^{2}$ : direct additive maternal heritability.

In males two models $\left(V_{\mathrm{a}}+V_{\mathrm{m}}, V_{\mathrm{a}}+V_{\mathrm{c}}\right)$ have the same lowest AIC for birth weight and weaning weight: in these models $V_{\mathrm{a}}$ did not differ between the two and $V_{\mathrm{m}}=V_{\mathrm{c}}$. Estimates of (co)variances based on full model averaging are shown in italics.

The html and online PDF versions have also been rectified, and now carry the corrected paper. 